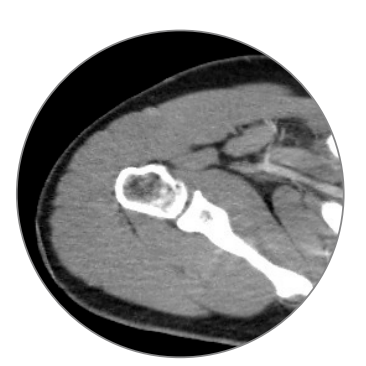

\section{Síndrome de Paget-Schrötter. Presentación de un caso}

\author{
Paget-Schröetter Syndrome. A Case Report
}

Daniel Antonio Rojas Padilla Helí de Jesús Rueda Chaparro' Miguel Eduardo Durán Gómez ${ }^{2}$ Luis Felipe Uriza Carrasco ${ }^{3}$

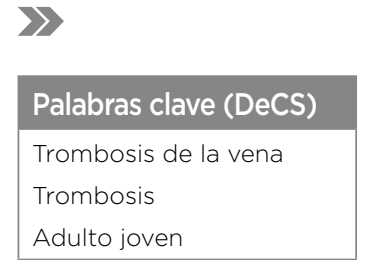

\section{Key words (MeSH)}

Venous thrombosis

Thrombosis

Young adult
Médico residente de tercer año de Radiología e imágenes diagnósticas. Departamento de Radiología e Imágenes Diagnósticas. Hospital Universitario San Ignacio. Pontificia Universidad Javeriana. Bogotá, D. C., Colombia.

2 Médico residente de primer año de Radiología e imágenes diagnósticas. Departamento de Radiología e Imágenes Diagnósticas. Hospital Universitario San Ignacio. Pontificia Universidad Javeriana. Bogotá, D. C., Colombia.

${ }^{3}$ Radiólogo. Departamento de Radiología e imágenes diagnósticas. Hospital Universitario San Ignacio. Pontificia Universidad Javeriana. Bogotá, D. C., Colombia.

\title{
Resumen
}

El síndrome Paget-Schrötter se define como la trombosis venosa profunda primaria de las extremidades superiores, atribuible a anomalías anatómicas obstructivas en la vena axilar o subclavia que alteran el retorno venoso, o por un esfuerzo muscular intenso. Por lo general, se presenta en adultos jóvenes sin antecedentes y se expresa clínicamente como dolor, edema espontáneo y grave de las extremidades superiores luego de una actividad física vigorosa, asociado a parestesias, debilidad y cianosis. Para el diagnóstico se necesita la combinación de la probabilidad clínica, el resultado del dímero D y la ultrasonografía. Su incidencia es aproximadamente de 1 a 2 personas por 100.000 habitantes al año y afecta a ambos sexos. A continuación se presenta el caso de un paciente con síndrome de Paget-Schrötter que consultó al servicio de urgencias en un hospital de tercer nivel.

\section{Summary}

Paget-Schroetter syndrome is defined as a primary deep vein thrombosis of the upper extremities due to obstructive anatomical anomalies in the axillary or subclavian vein that changes venous blood flow or due to intense muscular effort. It usually occurs in young adults with no previous history and its clinical manifestations are pain, spontaneous and severe edema of the upper extremities after stressful physical activity associated with paresthesias, weakness and cyanosis. Diagnosis requires a combination of clinical probability, D-dimer results and ultrasonography. It occurs in approximately 1-2 people per 100,000 inhabitants per year and affects both sexes. The following case is a patient with Paget-Schroetter syndrome which came to the ER at a fourth-level hospital.

\section{Introducción}

El síndrome de Paget-Schrötter se define como la trombosis venosa profunda primaria de las extremidades superiores secundaria a anomalías anatómicas obstructivas en la vena axilar o subclavia que alteran el retorno venoso, o por un esfuerzo muscular intenso. Por lo general, se presenta en adultos jóvenes sin antecedentes y se expresa clínicamente como dolor, edema espontáneo y grave de las extremidades superiores luego de una actividad física vigorosa, asociado a parestesias, debilidad y cianosis (1).

Es una entidad rara, corresponde al $5 \%$ de todas las trombosis venosas profundas y se presenta aproximadamente en 1-2 personas por 100.000 habitantes al año, en igual proporción en ambos sexos. Existe prevalencia asociada con factor V de Leiden, anticuerpos antifosfolípidos y mutaciones del gen de la protrombina $(1,2)$.

Para el diagnóstico es necesaria la combinación de la probabilidad clínica, el resultado del dímero D y la ultrasonografía.

\section{Presentación del caso}

Paciente masculino de 22 años de edad con cuadro clínico de un día de evolución, caracterizado por dolor en el miembro superior derecho asociado a edema y parestesias. El único antecedente relevante es que se trata de un individuo que practica levantamiento de pesas.

Al examen físico se encontró con edema distal extendido hasta el tercio proximal del brazo derecho, con leve coloración violácea, adecuado llenado capilar, con pulsos braquial y radial, sensibilidad y arcos de movilidad conservados.

Con la sospecha de posible trombosis venosa de causa no clara, se le realizó Doppler arterial y venoso del miembro superior derecho, la exploración de los vasos arteriales se encontró dentro de límites normales (figura 1). El Doppler venoso demostró trombosis venosa aguda de las vena subclavia y axilar derecha (figura 2). Tras haber descartado trombofilia y fenómeno procoagulante asociado a infección por SARS-CoV-2, se le practicó angioescanografía de vasos torácicos que confirmó trombosis aguda de la vena subclavia derecha. Por el antecedente de levantamiento de pesas, se sugirió en el diagnóstico diferencial el síndrome Paget-Schrötter (figura 3). Después de este diagnóstico, el servicio tratante inició terapia con anticoagulación plena con heparina de bajo peso molecular (enoxaparina) a dosis de $1 \mathrm{mg} / \mathrm{kg}$ cada 12 horas. A continuación, se realizó tratamiento endovascular mediante punción bajo guía 
ecográfica en la vena braquial, con posterior identificación del sitio de obstrucción por el trombo ya mencionado. Una vez identificado, se avanzó el sistema de tromboaspiración y se procedió a la inyección intravenosa de 5.000 UI de heparina no fraccionada, se logró avanzar hasta el tercio proximal de la vena subclavia y la vena innominada, se procedió a la angioplastia con balón de $8 \mathrm{~mm}$ en las venas braquial y axilar, y de $10 \mathrm{~mm}$ en las venas braquial, axilar y subclavia. En la flebografía de control se confirmó una adecuada permeabilidad de las venas braquial y axilar derechas, pero se evidenció trombo residual del $20 \%$ en el segmento subclavio (figuras $4 \mathrm{a}$ y $4 \mathrm{~b}$ ).

Durante la hospitalización, el paciente tuvo adecuada evolución clínica, sin complicaciones postoperatorias, por lo que se dio egreso con anticoagulación plena.

\section{Discusión}

La trombosis venosa profunda de la vena subclavia se divide en primaria y secundaria. La primaria también se conoce como síndrome de Paget-Schrötter o "trombosis de esfuerzo" y la secundaria, atribuible a inserción de dispositivos médicos intravasculares en la mayoría de los casos, trauma, trombofilia o enfermedad neoplásica (1).

La vena subclavia hace parte de la estructura vascular venosa que drena el miembro superior, su recorrido empieza en la unión de las venas axilar y cefálica adyacente al borde lateral del primer arco costal; discurre hacia la cavidad torácica con las siguientes relaciones anatómicas: anterior, con el músculo subclavio y el ligamento costoclavicular; posterior, con el músculo escaleno anterior; superior, con la clavícula, e inferior, con el primer arco costal (figura 5), justo antes de unirse con la vena yugular interna en el confluente yugulosubclavio. Al tener dos estructuras de tejido blando entre sus relaciones anatómicas (límites anterior y posterior), la hipertrofia del ligamento costoclavicular o del músculo escaleno anterior puede generar compresión sobre la vena subclavia, lo que disminuye su calibre, causa flujo lento y, por consiguiente, facilita la formación de trombos (1-3).

El síndrome de Paget-Schrötter fue descrito por primera vez en 1875 por James Paget, seguido en 1884 por von Schrötter (2). Entre los factores de riesgo se encuentran alteraciones anatómicas y el ejercicio muscular excesivo que conlleva a la hipertrofia de los músculos escalenos, principalmente el músculo escaleno anterior, el cual está en contacto con el borde posterior de la vena subclavia en su trayecto antes de ingresar a la cavidad torácica (figura 5) (2). La incidencia descrita en la literatura es baja, de 2:100.000 casos al año, con un pico de presentación alrededor de los 30 años y más común en hombres con una tasa de 2:1 respecto a las mujeres (1).

La sintomatología de esta entidad involucra edema, cambios en la coloración de la piel, circulación colateral en la región axilar y el hombro de la extremidad afectada (signo de Urschel), que usualmente aparece en la extremidad dominante. El $80 \%$ de los pacientes refieren el inicio de la sintomatología en las primeras 24 horas luego de realizar una actividad física vigorosa $(2,3)$.

Entre las modalidades de imagen diagnóstica, la ecografía Doppler tiene un valor supremamente valioso bajo la modalidad de Dopplercolor y espectral, con sensibilidad documentada que varía entre $71 \%$ y $100 \%$ y especificidad del $80 \%$ al $100 \%(3,4)$, al explorar los vasos sanguíneos que componen los sistemas venosos profundo y superficial de la extremidad afectada. Hallazgos como la ausencia de flujo a la exploración Doppler-color, disminución o pérdida de la fasicidad de los espectros venosos, sumado a una imagen ecogénica en el interior del vaso, confirman el diagnóstico.

Cuando el Doppler es inconcluso debido al artefacto de sombra acústica posterior que podrían generar las estructuras óseas del opérculo torácico o la presencia de gas en los casos de trauma, la angioescanografía de vasos en fase venosa tiene un papel protagónico para confirmar o descartar trombosis, al visualizar el defecto de opacificación hipodenso en la luz de la vena $(2,5)$. Hallazgos como la circulación colateral o la alteración en la densidad del tejido celular subcutáneo de la extremidad deben ser signos de alarma ante la sospecha de una trombosis, ya sea en la extremidades o de origen central $(1,2)$. Así mismo, la angiorresonancia de vasos venosos tiene utilidad favorable debido a que no expone al paciente a radiación ionizante y también tiene una buena resolución anatómica y de contraste. Se ha informado que la resonancia magnética en tiempo de vuelo y las adquisiciones después de la administración de gadolinio tienen una sensibilidad y especificidad del $71 \%$ y $89 \%$ para la primera y $50 \%$ y $80 \%$ para la segunda, respectivamente (1).

La flebografía de vasos de la extremidad junto con cavografía pueden ser diagnósticas y terapéuticas, agrupando la visualización del defecto de llenado intraluminal del vaso, presencia o no de circulación colateral y también como planeamiento quirúrgico inmediatamente antes del tratamiento percutáneo $(1,2)$.

El tratamiento multidisciplinario de esta enfermedad consiste en la anticoagulación sistémica, el manejo endovascular y la descompresión quirúrgica de la vena subclavia a través del opérculo torácico, por medio de la resección de la primera costilla junto a los músculos escaleno anterior y subclavio, y es este el manejo definitivo (6).

Inicialmente, se debe realizar la anticoagulación sistémica con heparinas de bajo peso molecular, anticoagulantes orales o antagonistas de la vitamina $\mathrm{K}$, que según la evidencia actual, cualquiera de las alternativas es igual de efectiva y segura $(1-3,7)$.

El tratamiento endovascular tiene como objetivo proporcionar un rápido alivio de los síntomas, prevenir la embolia pulmonar, el desarrollo del síndrome postrombótico y recuperar la funcionalidad temprana de la extremidad afectada. Este manejo involucra la trombectomía farmacológica con catéter, en la cual se realiza en principio una remodelación y extracción del trombo seguido por la infusión de agentes trombolíticos con el fin de recanalizar la luz de la vena. La evidencia actual muestra que este abordaje tiene mayor éxito que realizar únicamente aspiración del trombo, dado que logra el retorno venoso en una sola sesión, lo cual disminuye los tiempos de estancia hospitalaria y las tasas de sangrado $(3,6)$.

\section{Conclusión}

El síndrome de Paget-Schrötter es una entidad que si bien puede ser infrecuente, es necesario sospechar tanto las causas primarias como las secundarias. El examen físico con edema, cambios en la coloración de la piel y circulación colateral de la extremidad elevan la sospecha sumado al resultado de la toma de exámenes paraclínicos y las imágenes diagnósticas. El tratamiento incluye terapia anticoagulante, tratamiento endovascular e incluso tratamiento quirúrgico, por lo que debe hacerse un manejo multidisciplinario. El papel del radiólogo es fundamental cuando se sospecha esta entidad, ya que favorece el diagnóstico y el tratamiento individualizado del paciente. 


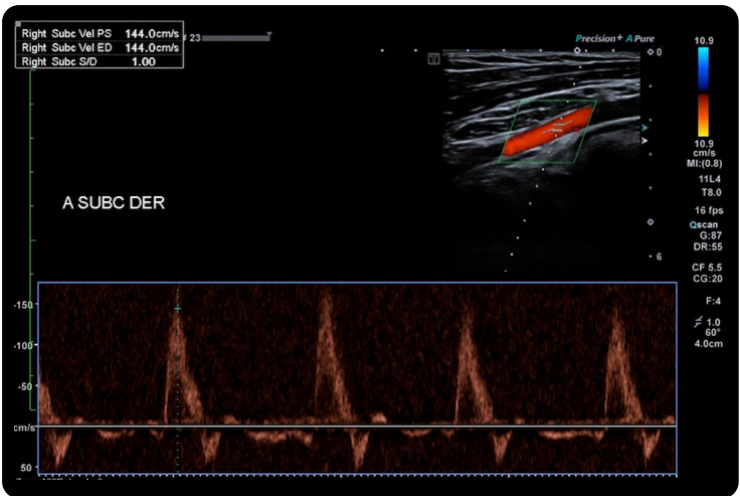

Figura 1. Ecografía Doppler de vasos arteriales del miembro superior derecho. Arteria subclavia permeable, con espectros trifásicos, anterógrados, de alta resistencia, dentro de límites normales.

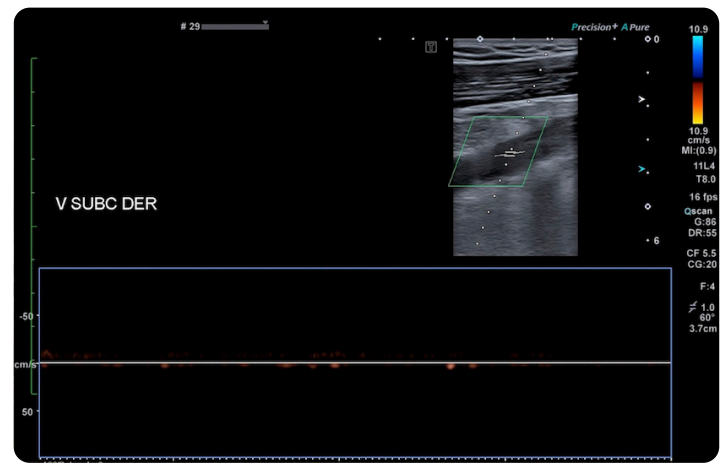

Figura 2. Ecografía Doppler de vasos venosos del miembro superior derecho. Dilatación y ocupación por material ecogénico dentro de la vena subclavia, que se extiende a la vena axilar derecha con ausencia de flujo tras la exploración Doppler-color y espectral.
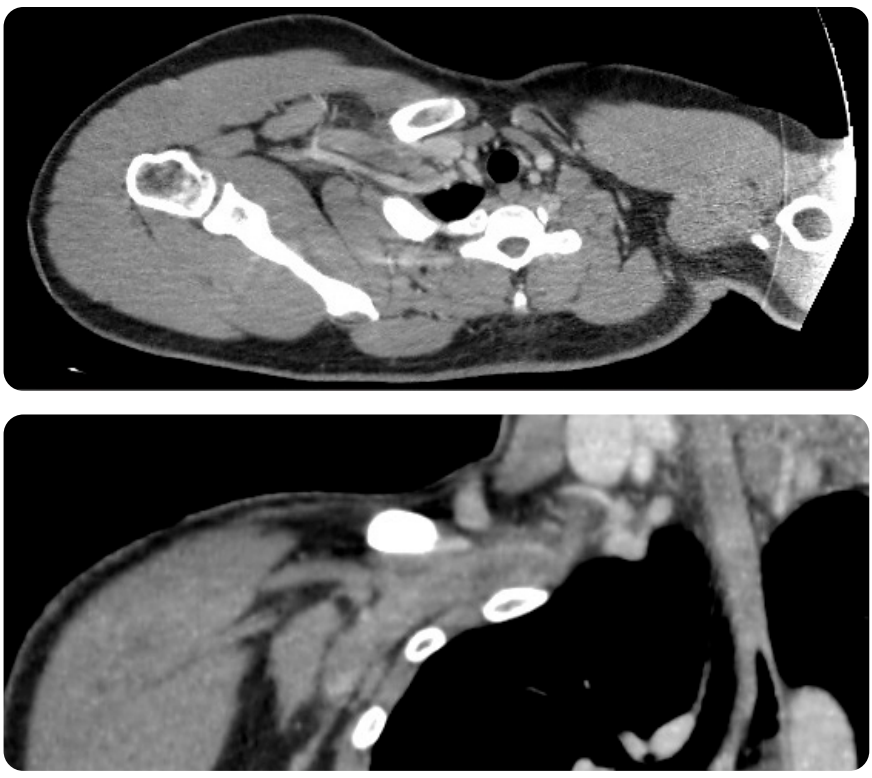

Figura 3. Angioescanografía de vasos venosos del miembro superior derecho. Se realizó una adquisición volumétrica helicoidal posterior a la administración endovenosa de medio de contraste yodado hidrosoluble no iónico, con el paciente en decúbito supino y posición de los brazos a ambos lados del paciente. a) Ventana para tejidos blandos, reconstrucción multiplanar posproceso en el eje de la vena subclavia y b) reconstrucción coronal. Dilatación y ausencia de opacificación de la vena subclavia en todo su trayecto, así como de la vena axilar tras la administración del medio de contraste endovenoso. Hay adecuada permeabilidad de las venas distales.
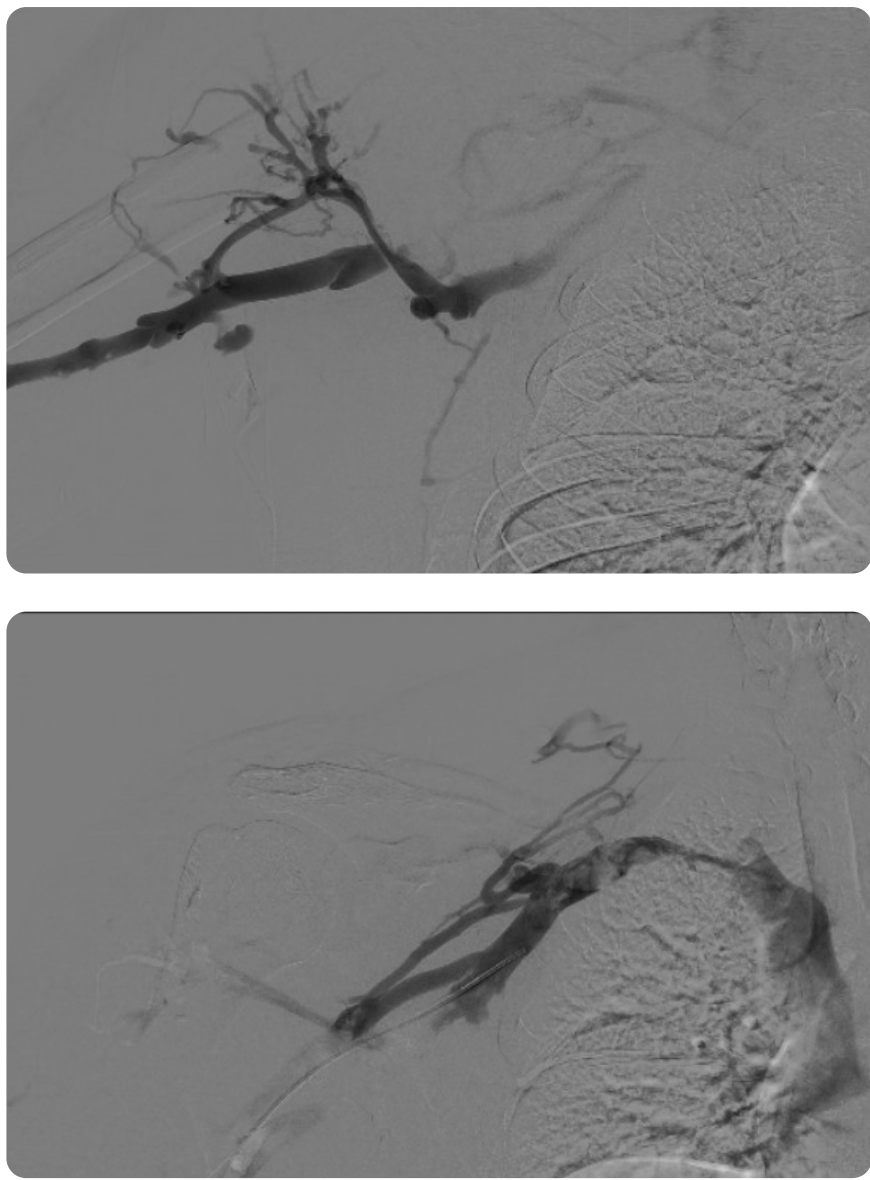

Figura 4. Flebografía del miembro superior derecho. a) Ausencia de opacificación de la vena axilar y subclavia. b) El paciente fue sometido a trombólisis y trombectomía mecánica, para lograr permeabilidad del segmento braquial y axilar con trombo residual del $20 \%$.

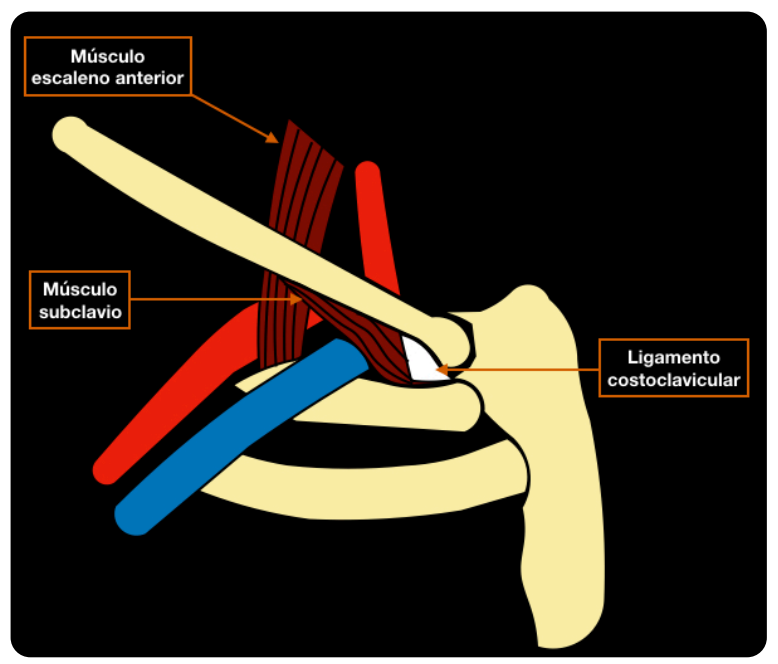

Figura 5. Esquema de las relaciones anatómicas de la vena subclavia. Fuente: Elaboración propia. 


\section{Referencias}

1. Bosch FTM, Nisio M Di, Büller HR, van Es N. Diagnostic and therapeutic management of upper extremity deep vein thrombosis. J Clin Med [Internet]. 2020;9(7):2069.

2. Illig KA, Doyle AJ. A comprehensive review of paget-schroetter syndrome. J Vasc Surg [Internet]. 2010;51(6):1538-47.

3. Ringhouse B, Jackson C. Bringing to light symptoms and treatments of effort thrombosis (paget-schroetter syndrome) in the military population, a case study. Mil Med [Internet]. 2017;182(5):e1826-9.

4. Chin EE, Zimmerman PT, Grant EG. Sonographic evaluation of upper extremity deep venous thrombosis. J Ultrasound Med [Internet]. 2005;24(6):829-38.

5. Brownie ER, Abuirqeba AA, Ohman JW, Rubin BG, Thompson RW. False-negative upper extremity ultrasound in the initial evaluation of patients with suspected subclavian vein thrombosis due to thoracic outlet syndrome (Paget-Schroetter syndrome). J Vasc Surg Venous Lymphat Disord [Internet]. 2020;8(1):118-26.

6. Thompson R. Comprehensive management of subclavian vein effort thrombosis Semin Intervent Radiol [Internet]. 2012;29(01):44-51.

7. Kärkkäinen JM, Nuutinen H, Riekkinen T, Sihvo E, Turtiainen J, Saari P, et al. Pharmacomechanical thrombectomy in paget-schroetter syndrome. Cardiovasc Intervent Radiol [Internet]. 2016;39(9):1272-9.

\section{Correspondencia}

Daniel Antonio Rojas Padilla

Carrera 7 \# 40-62

Departamento de Radiología e Imágenes Diagnósticas

Hospital Universitario San Ignacio

Bogotá, Colombia

drojasp@javeriana.edu.co

Recibido para evaluación: 20 de mayo de 2020

Aceptado para publicación: 18 de enero de 2021 